\title{
Oxidative Stress in Dog with Heart Failure: The Role of Dietary Fatty Acids and Antioxidants
}

\author{
Emmanuelle Sagols $^{1}$ and Nathalie Priymenko ${ }^{2}$ \\ ${ }^{1}$ ENVT, 2 allée des Cèdres 66330 Cabestany, France \\ ${ }^{2}$ ENVT, INRA, UMR 1089, Université de Toulouse, 31076 Toulouse, France \\ Correspondence should be addressed to Emmanuelle Sagols, emma.sagols@yahoo.fr
}

Received 30 December 2010; Accepted 14 February 2011

Academic Editor: Cristina Castillo Rodríguez

Copyright (c) 2011 E. Sagols and N. Priymenko. This is an open access article distributed under the Creative Commons Attribution License, which permits unrestricted use, distribution, and reproduction in any medium, provided the original work is properly cited.

\begin{abstract}
In dogs with heart failure, cell oxygenation and cellular metabolism do not work properly, leading to the production of a large amount of free radicals. In the organism, these free radicals are responsible of major cellular damages: this is oxidative stress. However, a suitable food intake plays an important role in limiting this phenomenon: on the one hand, the presence of essential fatty acids in the composition of membranes decreases sensitivity of cells to free radicals and constitutes a first protection against the oxidative stress; on the other hand, coenzyme Q10, vitamin E, and polyphenols are antioxidant molecules which can help cells to neutralize these free radicals.
\end{abstract}

\section{Introduction}

Life expectancy of domestic carnivores has been increasing a lot these last years, probably due to veterinary medicine progresses, leading to an increase of the old-age diseases. Nowadays, heart failure is one of the main causes of death in domestic carnivores: approximately $10 \%$ of dogs have heart troubles, which can evolve to a cardiac insufficiency and, in the end, to the animal death [1]. Although treatments can slow down this evolution, a well-adapted nutrition constitutes a major asset to improve the well-being and life expectancy of these animals.

Besides the energetic protein or salt requirements commonly expressed by the literature, a suitable food intake of fatty acids and antioxidants can play an important role in maintaining cardiac cells homeostasis and especially in managing oxidative stress.

\section{Oxidative Stress and Heart Failure}

In the organism, free radicals $\left(\mathrm{O}_{2}{ }^{\circ}, \mathrm{OH}^{\circ}, \mathrm{H}_{2} \mathrm{O}_{2} \ldots\right)$ are produced permanently via cellular metabolism. In physiological conditions, antioxidant enzymes (super oxide dismutase, glutathione peroxidase...) regulate this phenomenon.
However, when a large amount of free radicals is produced, these enzymes are overloaded, and free radicals induce major cellular damages: this is oxidative stress.

2.1. Free-Radical Production during Heart Failure. In dogs with heart failure, oxygenation cells do not occur properly [2], which leads to cellular metabolism dysfunction: the main free-radical sources in heart failure are mitochondria, where an uncoupling of the respiratory chain leads to the increase in free-radical production [3], Xanthine oxidases and NADPH oxidases [4]. This cellular metabolism dysfunction occurs at two levels. In a chronic way, the heart work of a dog with heart failure is insufficient to provide the normal oxygenation of all cells, which implies a dioxygen cellular chronic deficit and thus a regular production of free radicals. In an acute way, during the phenomenon of ischemia reperfusion, the cell ischemia induces a massive production of free radicals that are released in the organism when reperfusion occurs.

2.2. Cellular Consequences of Oxidative Stress in Heart Cells. Free radicals are molecules very unstable and toxic for cells. The fatty acids of cell membranes are the first molecules damaged by free radicals: indeed, free radicals induce 
a membrane lipid peroxidation and alter the stability and the permeability of these membranes. They also induce DNA damages and protein denaturation with oxidation and fragmentation of polypeptidic chains [5]. These cellular lesions are so important that they can lead to the apoptosis of cells [6]. As well as these effects on cellular components, free radicals also act as intracellular messenger leading to cardiac hypertrophy and myocardium remodelling, worsening cardiac insufficiency [4].

So, cardiac insufficiency is at the origin of a noxious state of cellular oxidative stress, which increases the cardiac cell dysfunctions and thus amplifies the phenomenon of oxidative stress.

\section{Role of Omega 3 Essential Fatty Acids in the Management of Oxidative Stress}

Fatty acids are carboxylic acids with long carbon chain with an even number of carbon atoms. They can be saturated or not according to the presence or absence of double bounds between the carbon atoms. Three fatty acid groups could be distinguished with the saturated fatty acids (not any double bound), the monounsaturated fatty acids (one double bound), or the polyunsaturated fatty acids (several double bounds). Some fatty acids are called "essentials" as mammals do not synthesize them, and they must then be present in the food to satisfy the organism needs. This is the case of long omega 3 and omega 6 fatty acids that possess their first double bound between the $3 \mathrm{rd}$ and the 4 th carbon and between the 6 th and the 7 th carbon of the carbon chain, respectively.

3.1. Role of Essential Fatty Acids in the Management of Oxidative Stress. The unsaturated fatty acids of cell membranes are the first damaged by the free radicals produced during cardiac insufficiency, this results in cell disorganization and cellular dysfunction. The presence of essential fatty acids in the composition of cell membranes decreases their sensitivity to free radicals and constitutes a first protection against the oxidative stress [7].

Essential fatty acids also play a role in scavenging free radicals produced within cells, which participate to protection of cell constituents. Indeed, in rats, a 7\% daily supplementation in omega 3 essential fatty acids increases the cellular concentration of super oxide dismutase in heart, making it more available to neutralize the free radicals produced by cellular metabolism [8]. Another study led in rats shows as well that a $60 \mathrm{mg} / \mathrm{kg} \alpha$-lipoïc injection decreases significantly the amount of free radicals produced during an oxidative stress phenomenon and is associated with an increase of the level of gluthatione peroxidase in cells [9]. However, all essential fatty acids are not equivalent: the omega 6 fatty acids, which are commonly known to be inflammation activators, do not induce the same benefits for the cardiac cells [1].

3.2. Source of Essential Fatty Acids. Omega 3 fatty acids can be found mainly in fat fishes, soya, colza, or linen oils (Table 1) [10]. Although the optimal dose of omega 3 essential fatty acids still remains to be determined, it would seem that the ratio omega 6 :omega 3 is very important. Indeed, if the quantity of fatty acids omega 3 brought is too important, there is a risk of lipid peroxidation. Then, the most adapted ratio seems to be $5: 1$ ratio [11].

Concerning cardiac insufficiency, essential fatty acids in cell membranes play a protective role against free radicals produced by cardiac cells also against free radicals released by other cells, especially when ischemia reperfusion phenomena occurs. However, antioxidants are also playing an important role to neutralize the free radicals upstream before cell membranes infringement.

\section{Role of Antioxidants in the Management of Oxidative Stress}

\subsection{Coenzyme Q10}

4.1.1. Roles of Coenzyme Q10 in the Management of Oxidative Stress. It is now well known that heart function is improved by a supplementation of coenzyme Q10 [12]. Indeed, the coenzyme Q10, which is a part of the respiratory chains of mitochondria, plays a role in the cell energy production. However, oxidative stress results from a dioxygen misuse by cells. So, we understand why the coenzyme Q10, which enters in the composition of respiratory chains of mitochondria, improves the cell energy production [2].

Nevertheless, the heart functioning improvement is also due to antioxidant properties of coenzyme Q10, particularly if an ischemia phenomenon occurs in the myocardium. The coenzyme Q10, with its antioxidant properties [13], helps to fight against the free radicals released later during reperfusion, thanks to two mechanisms: directly, by scavenging free radicals produced [14], and indirectly, by regenerating the active form of other antioxidant molecules [15]. Moreover, the coenzyme Q10 also intervenes in the energy production resumption after an ischemia phenomenon, improving the myocytes functioning [16].

4.1.2. Sources of Coenzyme Q10. Coenzyme Q10 can be synthesized from phenylalanine, acetyl Coenzyme A, tyrosine and by seven vitamins $\left(\mathrm{B}_{2}, \mathrm{~B}_{3}, \mathrm{~B}_{5}, \mathrm{~B}_{6}, \mathrm{~B}_{9}, \mathrm{~B}_{12}\right.$, and C). However, food can also supply coenzyme Q10: meat is particularly rich in coenzyme Q10 (Table 2) [17, 18]. An intake from 30 to $90 \mathrm{mg}$ by oral route, twice a day, is the dose most frequently recommended [1].

\subsection{Vitamine E and Selenium}

4.2.1. Antioxidant Properties of Vitamin E and Selenium. All the eight vitamin $\mathrm{E}$ isomers are fat-soluble vitamins with antioxidant properties, but the most active form is $\alpha$ tocopherol. By its antioxidant properties, vitamin E plays a cellular barrier role for the oxidant molecules produced by oxidative stress. In a study led in rats, a vitamin $\mathrm{E}$ supplementation allows an increase of its incorporation in the cell membranes and a decrease of the quantity of proteins oxidized in cells [19]. When the vitamin E is exceeded, 
glutathione peroxidase relieves vitamin $\mathrm{E}$ to neutralize the oxidant molecules. The main cofactor of this enzyme is selenium, and it is easily understandable which impact could have a deficit in selenium on its activity. On the other hand, an increase of the selenium intake seems to have no effect on the activity of glutathione peroxidase [20].

4.2.2. Sources of Vitamin E. Vitamin E is a molecule synthesized by plants. The minimum food contribution recommended by AAFCO is $50 \mathrm{UI} / \mathrm{kg}$ DM. Nevertheless, its intestinal absorption is widely influenced by the ration composition: the presence of polyunsaturated fatty acids oxidant agents implies an increase of vitamin $\mathrm{E}$ need; on the contrary, a ration containing monounsaturated fatty acids or selenium leads to a decrease of vitamin E necessary. So, there is no vitamin $\mathrm{E}$ recommended intake to obtain an antioxidant effect. However, in dog food, a maximum of $1000 \mathrm{UI} / \mathrm{kg}$ was fixed by the AAFCO. Indeed, vitamin E is a little toxic, and we can imagine an interesting antioxidant effect with such concentrations [21].

\subsection{Polyphenols}

4.3.1. Role of Polyphenols in the Management of Oxidative Stress. Polyphenols have recently attracted many scientists' attention. Indeed, for a long time, these molecules were considered as uninteresting for the organism, concerning nutritional level or health, but the progress of the analysis techniques allowed to understand better the role of these organic compounds. These molecules are synthesized by plants to respond to an environmental stress. They compose a wide family of chemical compounds, which contains more than 8000 different organic molecules. All the polyphenols are characterised by one or more benzene nuclei, where are fixed one or more alcohol groups $(-\mathrm{OH})[22]$.

Polyphenols have antioxidant properties which allow them to catch the free radicals produced during oxidative stress [23]. In a study led in rat, a contribution of $35 \mathrm{~mL}$ of a $90 \%$ pure polyphenols extract, once a day during 14 days, allows an increase of the quantity of polyphenols in the cardiomyocyte membranes and decreases significantly the noxious effects of the ischemia-reperfusion phenomena: improvement of the myocardium contractibility, decrease of cellular edema, and limit the dysfunctions in heart cells [24, 25]. In another study in rat, $50 \mathrm{mg} / \mathrm{kg}$ of quercetin neutralize the free radicals produced during ischemia reperfusion, enabling a decrease of cellular damages due to oxidative stress and an increase in the concentrations of glutathione peroxidase and glutathione reductase, which confirms the antioxidant properties of polyphenols [26].

4.3.2. Sources of Polyphenols. The available data concerning the polyphenol place in the food and their beneficial effects on health are at least vague. In food, polyphenols are mainly found in vegetables (Table 3 ). However, the determination of the food polyphenols composition is difficult because of the important variety of molecules. There is a big difference between the quantity of polyphenols contained
TABle 1: Main omega 3 fatty acid sources in food [10].

\begin{tabular}{lc}
\hline Source & Omega 3 fatty acids $(\mathrm{g} / 100 \mathrm{~g})$ \\
\hline Salmon & 3,2 \\
Linen oil & 20,3 \\
Colza oil & 9 \\
Soya oil & 5 \\
\hline
\end{tabular}

TABle 2: Coenzyme Q10 content in food [17, 18].

\begin{tabular}{lccc}
\hline \multirow{2}{*}{ Food } & & $\begin{array}{c}\text { Coenzyme Q10 } \\
(\mu \mathrm{g} / 100 \mathrm{~g} \text { wet weight }) \\
{[17]}\end{array}$ & $\begin{array}{c}\text { Coenzyme Q10 } \\
(\mu \mathrm{g} / 100 \text { g wet weight }) \\
{[18]}\end{array}$ \\
\hline \multirow{2}{*}{ Meat } & Beef & 3100 & $3030-4010$ \\
\multirow{2}{*}{ Fish } & Chicken & 1700 & $1710-2500$ \\
\multirow{2}{*}{ Vegetables } & Herring & $430-2700$ & $180-1300$ \\
& Broccoli & 660 & 701 \\
& Milk & 52 & 105 \\
\multicolumn{2}{c}{ Egg } & - & 31 \\
\hline \multicolumn{2}{c}{ Egtato } & 150 & 73 \\
\hline
\end{tabular}

Table 3: Polyphenol food availability in food [22].

\begin{tabular}{lc}
\hline Food & Polyphenols $(\mathrm{mg} / \mathrm{kg})$ \\
\hline Tea & $100-800$ \\
Black grape & $300-7500$ \\
Potato & $100-190$ \\
Soya & $200-900$ \\
Soya flour & $800-1800$ \\
Corn flour & 310 \\
Wheat flour & $70-90$ \\
Apple & $50-600$ \\
Beans & $350-550$ \\
Tomato & $2-15$ \\
\hline
\end{tabular}

in the food and the quantity effectively absorbed and used by the body: cooking, peeling fruits and vegetables, and preservation are so many factors which decrease the effective contribution of polyphenols in the body [22]. Moreover, the digestibility of polyphenols depends on their structure: the highly polymerized polyphenols cross with difficulty the intestinal wall. The small polymers are more easily absorbed and have a better systemic action, which implies a better nutritional value [22-27].

There is no study on the effect of polyphenols in domestic carnivores, but it is likely that the quantity of polyphenols ingested by dogs and cats via industrial or domestic food is very low. On the other hand, in a study led in rat, $50 \mathrm{mg} / \mathrm{kg}$ of weight of quercetin allow to neutralize the free radicals produced during ischemia reperfusion and so enables an antioxidant effect [26].

\section{Conclusion}

Although food has been recognized for several years to be an asset for the management of heart failure in animals, 
the place of antioxidants and essential fatty acids remains very limited. However, a suitable supplementation can play a major role against oxidative stress occurring during heart failure, avoiding cell disorganisation and cellular damages: on the one hand, thanks to a proper supplementation of antioxidants like Coenzyme Q10, vitamins, and polyphenols that neutralize free radicals produced by oxidative stress, and on the other hand, through omega 3 fatty acids that take part in the composition of cell membranes increasing the concentration of antioxidants in heart cells and making them less sensitive to free radicals. Although the studies led until now seem very promising, they were mainly led in vitro and/or in rats, and unfortunately, few studies have been led in dog and even less in the cardiac insufficient dog. Other studies should be led in domestic carnivores to confirm these first data.

In practice, dietary feed for cardiac insufficient animals are only supplemented with essential fatty acids with an omega 6/omega 3 report which can vary from 2 to 10 . Regarding the antioxidant molecule supplementations, they are often absent or below the contributions needed to have benefit for the heart. This is probably due to the difficulty to preserve a sufficient amount of antioxidants during the manufacturing process. In these conditions, the establishment of a home-made ration could be the best means to have a proper antioxidant supplementation although more complicated for the owner.

\section{References}

[1] L. M. Freeman and J. E. Rush, "Maladies cardiovasculaires : influence de l'alimentation," in Encyclopédie de la Nutrition Clinique Canine. Royal Canin, P. Pibot, V. Biourge, and D. Elliot, Eds., pp. 316-347, 2006.

[2] F. L. Rosenfeldt, S. Pepe, A. Linnane et al., "Coenzyme Q protects the aging heart against stress: studies in rats, human tissues, and patients," Annals of the New York Academy of Sciences, vol. 959, pp. 355-359, 2002.

[3] T. Ide, H. Tsutsui, S. Kinugawa et al., "Mitochondrial electron transport complex I is a potential source of oxygen free radicals in the failing myocardium," Circulation Research, vol. 85, no. 4, pp. 357-363, 1999.

[4] J. A. Byrne, D. J. Grieve, A. C. Cave, and A. M. Shah, "Oxidative stress and heart failure," Archives des Maladies du Coeur et des Vaisseaux, vol. 96, no. 3, pp. 214-221, 2003.

[5] S. Orrenius, "Mechanisms of oxidative cell damage," in Free Radicals: From Basic Science to Medicine, G. Poli, E. Albano, and M. U. Dianzani, Eds., pp. 47-64, MCBU, Bern, Switzerland, 1993.

[6] J. M. Hare, "Oxidative stress and apoptosis in heart failure progression," Circulation Research, vol. 89, no. 3, pp. 198-200, 2001.

[7] L. M. Freeman, J. E. Rush, J. J. Kehayias et al., "Nutritional alterations and the effect of fish oil supplementation in dogs with heart failure," Journal of Veterinary Internal Medicine, vol. 12, no. 6, pp. 440-448, 1998.

[8] R. Luostarinen, R. Wallin, and T. Saldeen, "Dietary (n-3) fatty acids increase superoxide dismutase activity and decrease thromboxane production in the rat heart," Nutrition Research, vol. 17, no. 1, pp. 163-175, 1997.
[9] A. Goraca, A. Piechota, and H. Huk-Kolega, "Effect of alphalipoic acid on LPS-induced oxidative stress in the heart," Journal of Physiology and Pharmacology, vol. 60, no. 1, pp. 6168, 2009.

[10] M. Feinberg, J. C. Favier, and J. Ireland-Ripert, "Répertoire général des aliments, Table de compositon des corps gras (tome 1)," in Technique et Documentation, INRA, CiquelRegal, 1987.

[11] R. C. Wander, J. A. Hall, J. L. Gradin, S. H. Du, and D. E. Jewell, "The ratio of dietary (n-6) to (n-3) fatty acids influences immune system function, eicosanoid metabolism, lipid peroxidation and vitamin E status in aged dogs," Journal of Nutrition, vol. 127, no. 6, pp. 1198-1205, 1997.

[12] P. H. Langsjoen and A. M. Langsjoen, "Overview of the use of coenzyme Q10 in cardiovascular disease," BioFactors, vol. 9, no. 2-4, pp. 273-284, 1999.

[13] K. A. Weant and K. M. Smith, "The role of coenzyme Q10 in heart failure," Annals of Pharmacotherapy, vol. 39, no. 9, pp. 1522-1526, 2005.

[14] J. S. Joo, "Coenzyme Q10 and cardiovascular health: to take or not to take, that is the question," Nutrition Bytes, vol. 10, p. 4, 2005.

[15] P. J. Quinn, J. P. Fabisiak, and V. E. Kagan, "Expansion of antioxidant function of vitamin E by coenzyme Q," BioFactors, vol. 9, no. 2-4, pp. 149-154, 1999.

[16] O. Hano, S. L. Thompson-Gorman, J. L. Zweier, and E. G. Lakatta, "Coenzyme Q enhances cardiac functional and metabolic recovery and reduces $\mathrm{Ca}^{2+}$ overload during postischemic reperfusion," American Journal of Physiology, vol. 266, no. 6, pp. H2174-H2181, 1994.

[17] C. Weber, A. Bysted, and G. Hølmer, "Coenzyme Q10 in the diet-daily intake and relative bioavailability," Molecular Aspects of Medicine, vol. 18, pp. S251-S254, 1997.

[18] H. Kubo, K. Fuj II, T. Kawabe, S. Matsumoto, H. Kishida, and K. Hosoe, "Food content of ubiquinol-10 and ubiquinone-10 in the Japanese diet," Journal of Food Composition and Analysis, vol. 21, no. 3, pp. 199-210, 2008.

[19] J. M. Berthiaume, P. J. Oliveira, M. W. Fariss, and K. B. Wallace, "Dietary vitamin E decreases doxorubicin-induced oxidative stress without preventing mitochondrial dysfunction," Cardiovascular Toxicology, vol. 5, no. 3, pp. 257-267, 2005.

[20] G. Flores-Mateo, A. Navas-Acien, R. Pastor-Barriuso, and E. Guallar, "Selenium and coronary heart disease: a metaanalysis," American Journal of Clinical Nutrition, vol. 84, no. 4, pp. 762-773, 2006.

[21] K. L. Gross, K. J. Wedekind, and C. S. Cowell, "Nutriments," in Nutrition Clinique des Animaux de Compagnie, M. S. Hand, C. D. Thatcher, R. L. Remillard, and P. Roudebush, Eds., pp. 87-109, Mark Morris Institute, Turin, Italy, 4th edition, 2000.

[22] C. Manach, A. Scalbert, C. Morand, C. Rémésy, and L. Jiménez, "Polyphenols: food sources and bioavailability," American Journal of Clinical Nutrition, vol. 79, no. 5, pp. 727747, 2004.

[23] P. Stanely Mainzen Prince and M. Karthick, "Preventive effect of rutin on lipids, lipoproteins and ATPase in normal and isoproterenol-induced myocardial infarction in rats," Journal of Biochemical and Molecular Toxicology, vol. 21, pp. 1-6, 2007.

[24] S. Mirwa, K. Yamazaki, S.-H. Hyon, and M. Komeda, "A novel method of "preparative" myocardial protection using green tea polyphenols in oral uptake," Interactive CardioVascular and Thoracic Surgery, vol. 3, pp. 612-615, 2004.

[25] J. Nečas, L. Bartošíková, T. Florian et al., "Protective effects of the flavonoids osajin and pomiferin on heart ischemia- 
reperfusion," Ceska a Slovenska Farmacie, vol. 55, no. 4, pp. 168-174, 2006.

[26] M. Ikizler, N. Erkasap, S. Dernek, T. Kural, and Z. Kaygisiz, "Dietary polyphenol quercetin protects rat hearts during reperfusion: enhanced antioxidant capacity with chronic treatment," Anadolu Kardiyoloji Dergisi, vol. 7, no. 4, pp. 404410, 2007.

[27] A. Scalbert and G. Williamson, "Dietary intake and bioavailability of polyphenols," Journal of Nutrition, vol. 130, no. 8, pp. 2073S-2085S, 2000. 

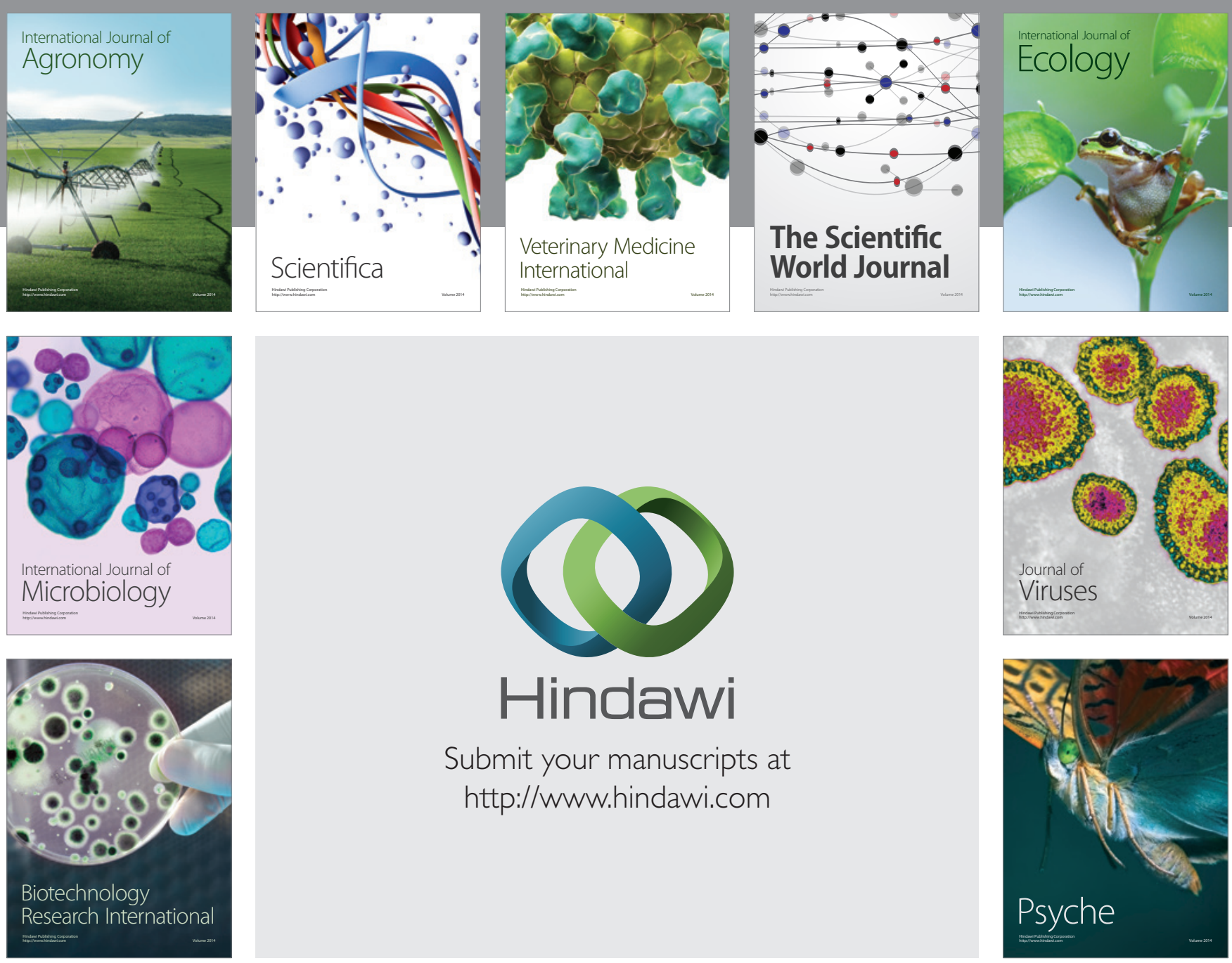

Submit your manuscripts at

http://www.hindawi.com
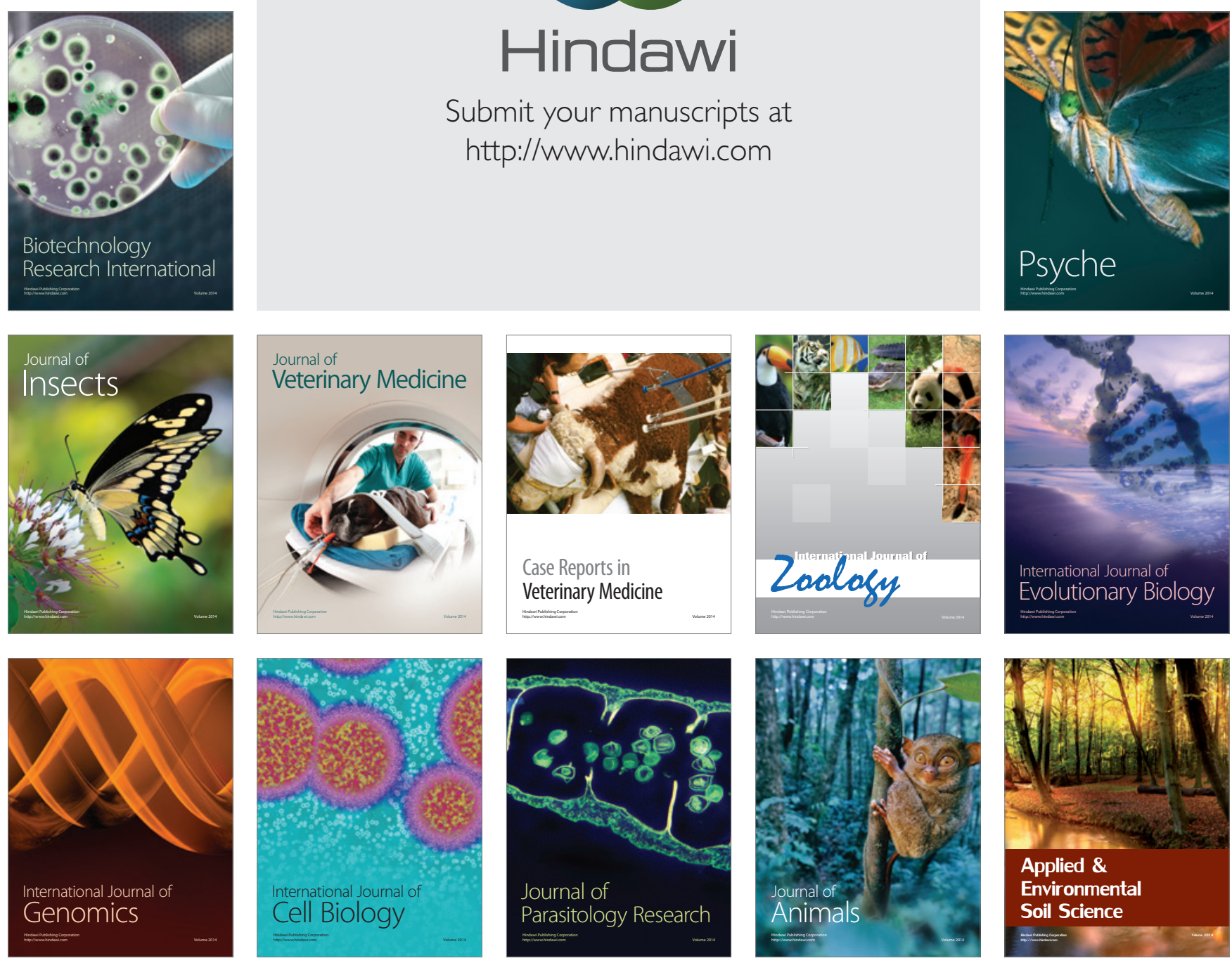